\title{
Dynamic Protein Acetylation in Plant-Pathogen Interactions
}

\author{
Gaoyuan Song and Justin W. Walley* \\ Department of Plant Pathology and Microbiology, lowa State University, Ames, IA, USA
}

Pathogen infection triggers complex molecular perturbations within host cells that results in either resistance or susceptibility. Protein acetylation is an emerging biochemical modification that appears to play central roles during host-pathogen interactions. To date, research in this area has focused on two main themes linking protein acetylation to plant immune signaling. Firstly, it has been established that proper gene expression during defense responses requires modulation of histone acetylation within target gene promoter regions. Second, some pathogens can deliver effector molecules that encode acetyltransferases directly within the host cell to modify acetylation of specific host proteins. Collectively these findings suggest that the acetylation level for a range of host proteins may be modulated to alter the outcome of pathogen infection. This review will focus on summarizing our current understanding of the roles of protein acetylation in plant defense and highlight the utility of proteomics approaches to uncover the complete repertoire of acetylation changes triggered by

OPEN ACCESS

Edited by:

Mark Findlay Belmonte,

University of Manitoba, Canada

Reviewed by:

Hans Thordal-Christensen, University of Copenhagen, Denmark

Biswapriya Biswavas Misra, University of Florida, USA

*Correspondence: Justin W. Walley jwalley@iastate.edu

Specialty section: This article was submitted to Plant Biotic Interactions, a section of the journal Frontiers in Plant Science

Received: 31 December 2015 Accepted: 18 March 2016 Published: 30 March 2016

Citation: Song $G$ and Walley JW (2016) Dynamic Protein Acetylation in Plant-Pathogen Interactions.

Front. Plant Sci. 7:421. doi: 10.3389/fpls.2016.00421 pathogen infection.

Keywords: acetylation, plant-pathogen interaction, defense, proteomics, post-translational modification

\section{INTRODUCTION}

Protein lysine acetylation is a reversible covalent modification that was first discovered on histones more than 50 years ago (Phillips, 1963; Allfrey et al., 1964; Verdin and Ott, 2015). In general hyperacetylation of histone proteins is associated with an open chromatin state and active transcription whereas histone deacetylation is associated with closed chromatin and a repressed transcriptional state. Additionally, histone acetylation recruits "reader" proteins (e.g., bromodomain containing proteins) that bind acetylated lysines enabling further modulation of the transcriptional state (Kouzarides, 2007; Verdin and Ott, 2015).

While protein acetylation was originally discovered on histones specifically it has long been known that non-histone proteins are also acetylated (Sterner et al., 1978; Verdin and Ott, 2015). Initially, studies focused on the role of non-histone acetylation of individual proteins. These studies demonstrated that many different types of proteins are acetylated, such as transcription factors, nuclear receptors, cytoskeletal proteins, and enzymes involved in metabolism. Additionally, acetylation was shown to modify protein function by affecting the three-dimensional structure, activity, stability, transportation and/or degradation of non-histone proteins (Glozak et al., 2005; Singh et al., 2010; Verdin and Ott, 2015). Due to the growing recognition of the importance and

Abbreviations: ET, Ethylene; ETI, effector-triggered immunity; HATs, histone acetyltransfersases; HDACs, histone deactylases; HDACi, histone deacetylase inhibitor; JA, jasmonic acid; LC-MS/MS, liquid chromatography tandem mass spectrometry; MS, mass spectrometry; NLR, nucleotide-binding/leucine-rich repeat receptor; PRR, pattern recognition receptor; SA, salicylic acid. 
potential biological impact of protein acetylation a number of labs worked to develop proteomic methodology to globally detect and quantify lysine acetylation.

\section{GLOBAL MS PROTEOMICS}

In the past two decades the field of MS based proteomics has rapidly matured to the point where we can routinely detect and quantify 5-10 1000 proteins in a single run (Nagaraj et al., 2011; Walley et al., 2013, 2015). However, the low abundance of acetylated proteins prevented global identification and quantification of lysine acetylation. This challenge was recently overcome by the development of pan anti-acetyllysine antibodies that recognize acetylated lysine irrespective of surrounding amino acids. By coupling acetyllysine immunopurification with MS based proteomics researchers are now able to globally profile lysine acetylation (Choudhary et al., 2009; Mertins et al., 2013). In this approach the anti-acetyllysine antibodies are employed in a technical strategy similar to the one outlined in Figure 1. Specifically, total proteins are extracted from cells or tissues, then the total proteins are digested to peptides, and the acetylated peptides are enriched using the anti-acetyllysine

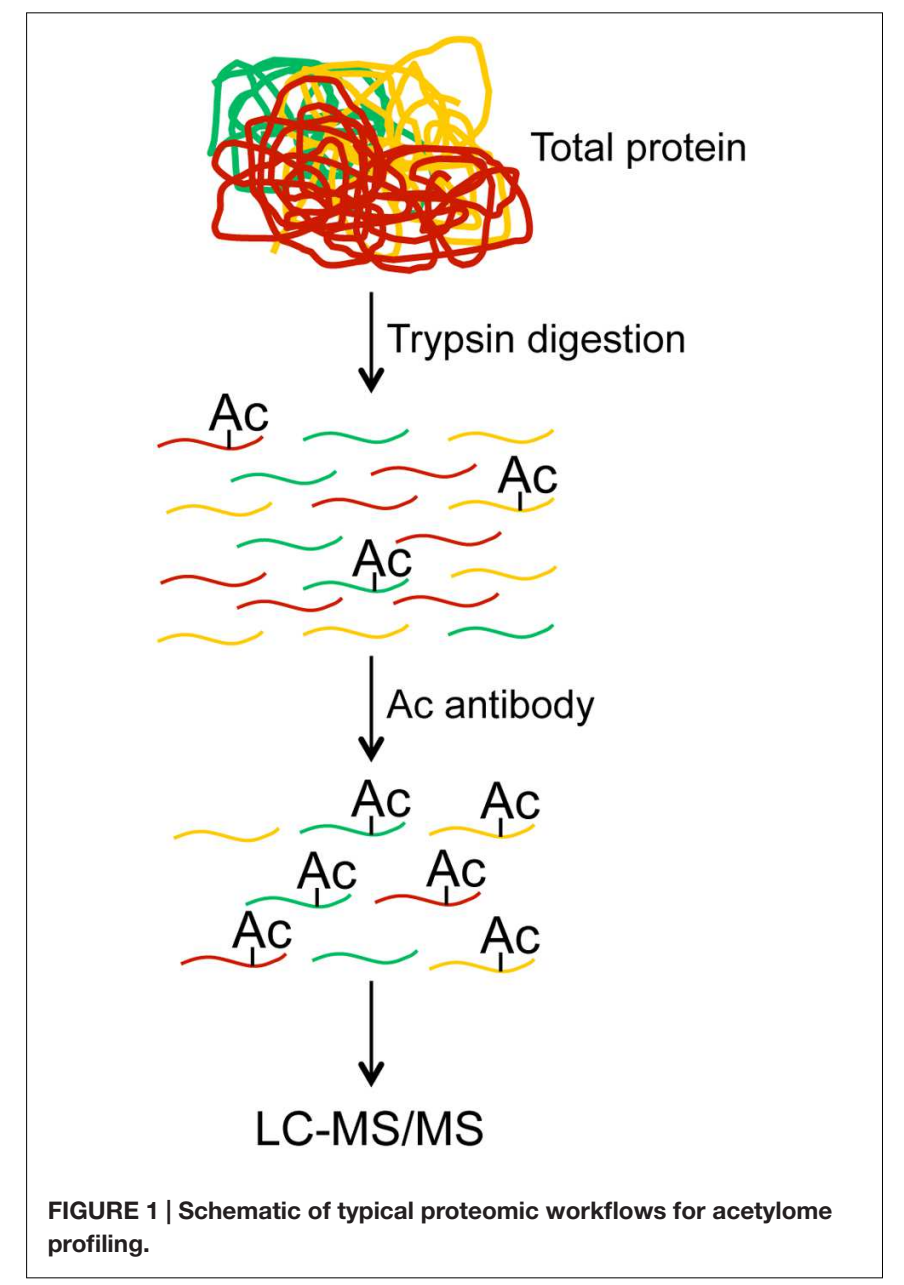

antibodies. Following enrichment the acetylated peptides are detected and quantified by using LC-MS/MS methods. Using this methodology, 100s and 1000s of acetylated sites have been identified in plants and non-plant eukaryotic systems, respectively. Organisms that have been utilized for either global or organellar acetylome profiling include Arabidopsis (Finkemeier et al., 2011; Wu et al., 2011; Konig et al., 2014), rice (Nallamilli et al., 2014), soybean (Smith-Hammond et al., 2014b), pea (Smith-Hammond et al., 2014a), grape (Melo-Braga et al., 2012), strawberry (Fang et al., 2015), human (Choudhary et al., 2009; Zhao et al., 2010; Barjaktarovic et al., 2015; Liu et al., 2015; Scholz et al., 2015; Wu et al., 2015), mouse (Yang et al., 2011; Chen et al., 2012; Fritz et al., 2012; Hebert et al., 2013; Masri et al., 2013; Holper et al., 2015; Kim et al., 2015), rat (Bouchut et al., 2015), Drosophila (Weinert et al., 2011; Feller et al., 2015), silkworm (Nie et al., 2015), yeast (Downey et al., 2015), Toxoplasma gondii (Xue et al., 2013), Escherichia coli (Zhang et al., 2013; Castano-Cerezo et al., 2014), and other bacteria (Okanishi et al., 2013; Wu et al., 2013; Liao et al., 2014; Liu et al., 2014; Pan et al., 2014; Kosono et al., 2015; Mo et al., 2015; Xie et al., 2015). Collectively, these studies demonstrate that non-histone acetylation is a common modification in different systems and suggest that acetylation plays and essential role in a myriad of biological processes.

\section{ENZYMATIC AND NON-ENZYMATIC AC}

Lysine acetylation is typically regulated by enzymes that add or remove acetyl groups. Specifically, lysine acetyltransferases (also termed HATs) have been shown to acetylate both histone and non-histone proteins (Sterner and Berger, 2000). Lysine acetyltransferases are divided, based on homology, into three different families, GNAT, MYST, and CBP/P300 (Kouzarides, 2007). Conversely, acetyl groups are removed from the acetylated proteins by lysine deacetylases (also termed HDACs; Kouzarides, 2007; Haery et al., 2015). Thus, protein acetylation levels are dynamically regulated by lysine acetyltransferases and deacetylases. Intriguingly, recent studies have demonstrated that protein acetylation is not only controlled enzymatically, but that it is also modulated non-enzymatically by metabolic intermediates including Acetyl-CoA and $\mathrm{NAD}^{+}$, which is required for activity of sirtuin type deacetylases (Choudhary et al., 2009; Cai et al., 2011; Lu and Thompson, 2012; Shen et al., 2015).

\section{HISTONE AC AND DEFENSE IN PLANTS}

Acetylation is a common modification of histones 3 and 4 . Generally, histone acetylation is enriched in the promoter region of genes, which functions to open the chromatin and enable gene expression (Figure 2). Studies have found that the expression level of HAT genes is induced by treatment with hormones as well as pathogen infection (Liu et al., 2012; Xu et al., 2015). Consistently, the level and pattern of histone acetylation is altered by pathogen infection. Finally, the maize fungal pathogen 


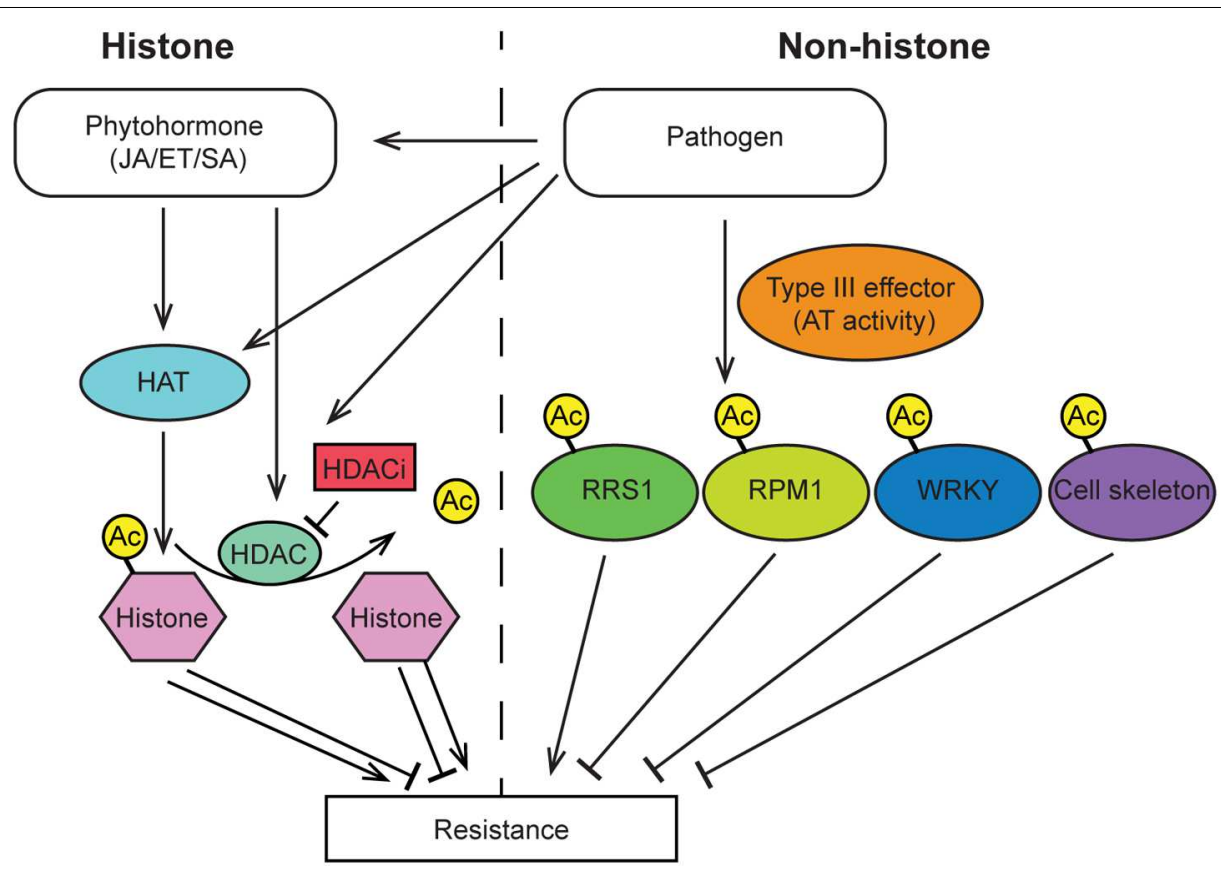

FIGURE 2 | Overview of histone and non-histone protein acetylation events that have been demonstrated to alter plant immunity. Pathogen infection results in modulation of HAT and HDAC activity, which alters the histone acetylation state of specific defense gene promoters thereby promoting either susceptibility or resistance. Several pathogen effector proteins encode acetyltransferase enzymes that directly acetylate host proteins and alter plant immunity. JA, jasmonic acid; ET, ethylene; SA, salicylic acid; HAT, histone acetyltransferase; HDAC, histone deacetylase; HDACi, histone deacetylase inhibitor; RRS1, Toll/Interleukin1 receptor type R protein; RPM1, intracellular nucleotide binding-leucine-rich repeat R protein.

Cochliobolus carbonum produces the effector molecule HC-toxin, which functions as a HDACi and is required for pathogen virulence (Johal and Briggs, 1992; Brosch et al., 1995; Ransom and Walton, 1997; Sindhu et al., 2008). Taken together these studies indicate that histone acetylation levels may play an important role in defense.

In line with these observations, a direct role for HDACs in modulating histone acetylation of defense genes and thereby plant resistance has been shown. The transcription level of Histone Deacetylase701 (HDT701), a member of the plantspecific HD2 subfamily of HDACs in rice, is increased in the compatible reaction and decreased in the incompatible reaction after infection by the fungal pathogen Magnaporthe oryzae (Ding et al., 2012). Critically, overexpression of HDT701 in transgenic rice leads to decreased levels of histone $\mathrm{H} 4$ acetylation and enhanced susceptibility to the rice pathogens M. oryzae and Xanthomonas oryzae pv. oryzae (Xoo). In contrast, silencing of HDT701 in transgenic rice causes elevated levels of histone $\mathrm{H} 4$ acetylation and elevated transcription of PRR and defense-related genes, increased generation of reactive oxygen species after pathogen-associated molecular pattern elicitor treatment, as well as enhanced resistance to both $M$. oryzae and Xoo.

In Arabidopsis, the RPD3-type histone deacetylases HDA6 and HDA19 have been extensively studied in the context of plant immunity. HDA19 modulates histone acetylation and is a positive regulator of JA/ET signaling pathways. Consistently, HDA19 modulates resistance to pathogens sensitive to JA/ET mediated immunity such as Alternaria brassicicola (Zhou et al., 2005). Conversely, HDA19 appears to play a negative role in SA mediated signaling and defense (Choi et al., 2012). Furthermore, HDA19 interacts with the transcription factors WRKY38 and WRKY62, which are negative regulators of SA defense signaling, to fine tune basal defense responses (Kim et al., 2008). Finally, HDA6 acts as a corepressor with JA-Zim domain (JAZ) proteins to repress EIN3/EIL1 dependent transcriptional responses and thereby JA signaling.

Histone acetyltransfersases have also been demonstrated to modulate Arabidopsis immunity via Elongator mediated gene regulation. Recent studies established that Arabidopsis Elongator complex mutants exhibit altered histone acetylation and target gene expression patterns, leading to altered pathogen resistance phenotypes. Specifically, mutation of Elongator subunit 2 (ELP2) reduces the histone acetylation level in the coding region of several plant defense genes, including PLANT DEFENSIN1.2 (PDF1.2), WRKY33 and OCTADECANOID-RESPONSIVE ARABIDOPSIS AP2/ERF59 (ORA59), which results in the repression of these genes and leads to suppression of plant defense (Wang et al., 2013, 2015). Mutation of another Elongator complex subunit, AtELP3, results in similar immune deficiencies as ELP2. AtELP3 has also been demonstrated to have HAT activity. Collectively these findings indicate that the Elongator complex is involved in both basal immunity and ETI (Defraia et al., 2013). 


\section{NON-HISTONE Ac IN PLANT IMMUNITY}

While the majority of research has investigated the role of histone acetylation in defense there are several studies that have established a role for non-histone protein acetylation in plant immunity. For instance, pathogen produced type III effectors can acetylate selected non-histone proteins in host cells, thereby triggering plant immunity response (Figure 2). One example of such an interaction is from the type III secreted effector, HopZ1a, which is secreted by Pseudomonas syringae and functions as an acetyltransferase. HopZ1 is able to self-acetylate and acetylate tubulin, which results in the destruction of plant microtubule networks, inhibits protein secretion and ultimately suppresses cell-wall mediated defense (Lee et al., 2012). A similar mechanism was found for the effector protein AvrBsT that also acts as an acetyltransferase and acetylates ACIP1, which is required for plant defense. Acetylation of ACIP1 alters the co-localization pattern of ACIP1 and microtubules (Cheong et al., 2014). Additionally, another type III secreted effector, PopP2, a YopJ-like effector from the soil borne root pathogen Ralstonia solanacearum, also has acetyltransferase activity. PopP2 directly acetylates the C-terminal WRKY transcription factor domain of the NLR RRS1 as well as WRKY transcription factors. Acetylation of RRS1 or WRKYs abolishes DNA binding activity. In the case of RRS1 acetylation, RPS4 dependent immunity is activated. Conversely, acetylation of WRKY transcription factors results in immune suppression (Tasset et al., 2010; Le Roux et al., 2015; Sarris et al., 2015). Finally, a new type III effecter HopZ3 from the plant pathogen $P$. syringae, have been found to acetylate multiple members of the RPM1 immune complex and depress plant immunity response (Lee et al., 2015).

\section{REFERENCES}

Allfrey, V. G., Faulkner, R., and Mirsky, A. E. (1964). Acetylation and methylation of histones and their possible role in the regulation of RNA synthesis. Proc. Natl. Acad. Sci. U.S.A. 51, 786-794. doi: 10.1073/pnas.51.5.786

Barjaktarovic, Z., Kempf, S. J., Sriharshan, A., Merl-Pham, J., Atkinson, M. J., and Tapio, S. (2015). Ionizing radiation induces immediate protein acetylation changes in human cardiac microvascular endothelial cells. J. Radiat. Res. 56, 623-632. doi: 10.1093/jrr/rrv014

Bouchut, A., Chawla, A. R., Jeffers, V., Hudmon, A., and Sullivan, W. J. Jr. (2015). Proteome-wide lysine acetylation in cortical astrocytes and alterations that occur during infection with brain parasite Toxoplasma gondii. PLoS ONE 10:e0117966. doi: 10.1371/journal.pone.0117966

Brosch, G., Ransom, R., Lechner, T., Walton, J. D., and Loidl, P. (1995). Inhibition of maize histone deacetylases by HC toxin, the host-selective toxin of Cochliobolus carbonum. Plant Cell 7, 1941-1950. doi: 10.2307/ 3870201

Cai, L., Sutter, B. M., Li, B., and Tu, B. P. (2011). Acetyl-CoA induces cell growth and proliferation by promoting the acetylation of histones at growth genes. Mol. Cell. 42, 426-437. doi: 10.1016/j.molcel.2011.05.004

Castano-Cerezo, S., Bernal, V., Post, H., Fuhrer, T., Cappadona, S., SanchezDiaz, N. C., et al. (2014). Protein acetylation affects acetate metabolism, motility and acid stress response in Escherichia coli. Mol. Syst. Biol. 10:762. doi: 10.15252/msb.20145227

Chen, Y., Zhao, W., Yang, J. S., Cheng, Z., Luo, H., Lu, Z., et al. (2012). Quantitative acetylome analysis reveals the roles of SIRT1 in regulating diverse

\section{PERSPECTIVE}

Lysine acetylation has emerged as a major post-translational modification impacting a diverse array of cellular processes. In the context of plant defense signaling it is well established that modulation of histone acetylation levels of defense genes is critical for appropriate immune responses. There is also mounting evidence that acetylation of non-histone proteins impacts plant immunity. However, to date non-histone protein acetylation of plant proteins has only been shown to result from pathogen effectors that encode acetyltransferase enzymes. This raises the question of whether plant HATs or HDACs directly modulate acetylation status of non-histone proteins during pathogen infection. The recent development of robust proteomic methodologies to globally identify and quantify lysine acetylation enables us to now identify proteome-wide changes in acetylation triggered during immune responses. Detailed follow-up studies of specific alterations in acetylation triggered by pathogen infection should shed light on whether plants directly modulate non-histone protein acetylation during defense signaling.

\section{AUTHOR CONTRIBUTIONS}

All authors listed, have made substantial, direct and intellectual contribution to the work, and approved it for publication.

\section{FUNDING}

Funding was provided by a start-up grant to JW from Iowa State University.

substrates and cellular pathways. Mol. Cell. Proteomics 11, 1048-1062. doi: 10.1074/mcp.M112.019547

Cheong, M. S., Kirik, A., Kim, J. G., Frame, K., Kirik, V., and Mudgett, M. B. (2014). AvrBsT acetylates Arabidopsis ACIP1, a protein that associates with microtubules and is required for immunity. PLoS Pathog. 10:e1003952. doi: 10.1371/journal.ppat.1003952

Choi, S. M., Song, H. R., Han, S. K., Han, M., Kim, C. Y., Park, J., et al. (2012). HDA19 is required for the repression of salicylic acid biosynthesis and salicylic acid-mediated defense responses in Arabidopsis. Plant J. 71, 135-146. doi: 10.1111/j.1365-313X.2012.04977.x

Choudhary, C., Kumar, C., Gnad, F., Nielsen, M. L., Rehman, M., Walther, T. C., et al. (2009). Lysine acetylation targets protein complexes and coregulates major cellular functions. Science 325, 834-840. doi: 10.1126/science. 1175371

Defraia, C. T., Wang, Y., Yao, J., and Mou, Z. (2013). Elongator subunit 3 positively regulates plant immunity through its histone acetyltransferase and radical S-adenosylmethionine domains. BMC Plant Biol. 13:102. doi: 10.1186/14712229-13-102

Ding, B., Bellizzi Mdel, R., Ning, Y., Meyers, B. C., and Wang, G. L. (2012). HDT701, a histone $\mathrm{H} 4$ deacetylase, negatively regulates plant innate immunity by modulating histone $\mathrm{H} 4$ acetylation of defense-related genes in rice. Plant Cell 24, 3783-3794. doi: 10.1105/tpc.112.101972

Downey, M., Johnson, J. R., Davey, N. E., Newton, B. W., Johnson, T. L., Galaang, S., et al. (2015). Acetylome profiling reveals overlap in the regulation of diverse processes by sirtuins, gen5, and esa1. Mol. Cell. Proteomics 14, 162-176. doi: $10.1074 /$ mcp.M114.043141 
Fang, X., Chen, W., Zhao, Y., Ruan, S., Zhang, H., Yan, C., et al. (2015). Global analysis of lysine acetylation in strawberry leaves. Front. Plant Sci. 6:739.

Feller, C., Forne, I., Imhof, A., and Becker, P. B. (2015). Global and specific responses of the histone acetylome to systematic perturbation. Mol. Cell 57, 559-571. doi: 10.1016/j.molcel.2014.12.008

Finkemeier, I., Laxa, M., Miguet, L., Howden, A. J., and Sweetlove, L. J. (2011). Proteins of diverse function and subcellular location are lysine acetylated in Arabidopsis. Plant Physiol. 155, 1779-1790. doi: 10.1104/pp.110.171595

Fritz, K. S., Galligan, J. J., Hirschey, M. D., Verdin, E., and Petersen, D. R. (2012). Mitochondrial acetylome analysis in a mouse model of alcohol-induced liver injury utilizing SIRT3 knockout mice. J. Proteome Res. 11, 1633-1643. doi: $10.1021 /$ pr2008384

Glozak, M. A., Sengupta, N., Zhang, X., and Seto, E. (2005). Acetylation and deacetylation of non-histone proteins. Gene 363, 15-23. doi: 10.1016/j.gene.2005.09.010

Haery, L., Thompson, R. C., and Gilmore, T. D. (2015). Histone acetyltransferases and histone deacetylases in B- and T-cell development, physiology and malignancy. Genes Cancer 6, 184-213.

Hebert, A. S., Dittenhafer-Reed, K. E., Yu, W., Bailey, D. J., Selen, E. S., Boersma, M. D., et al. (2013). Calorie restriction and SIRT3 trigger global reprogramming of the mitochondrial protein acetylome. Mol. Cell. 49, 186-199. doi: 10.1016/j.molcel.2012.10.024

Holper, S., Nolte, H., Bober, E., Braun, T., and Kruger, M. (2015). Dissection of metabolic pathways in the $\mathrm{Db} / \mathrm{Db}$ mouse model by integrative proteome and acetylome analysis. Mol. Biosyst. 11, 908-922. doi: 10.1039/c4m b00490f

Johal, G. S., and Briggs, S. P. (1992). Reductase activity encoded by the HM1 disease resistance gene in maize. Science 258, 985-987. doi: 10.1126/science.1359642

Kim, K. C., Lai, Z., Fan, B., and Chen, Z. (2008). Arabidopsis WRKY38 and WRKY62 transcription factors interact with histone deacetylase 19 in basal defense. Plant Cell 20, 2357-2371. doi: 10.1105/tpc.107.055566

Kim, S. J., Kwon, O. K., Ki, S. H., Jeong, T. C., and Lee, S. (2015). Characterization of novel mechanisms for steatosis from global protein hyperacetylation in ethanolinduced mouse hepatocytes. Biochem. Biophys. Res. Commun. 463, 832-838. doi: 10.1016/j.bbrc.2015.04.154

Konig, A. C., Hartl, M., Boersema, P. J., Mann, M., and Finkemeier, I. (2014). The mitochondrial lysine acetylome of Arabidopsis. Mitochondrion 19(Pt B), 252-260.

Kosono, S., Tamura, M., Suzuki, S., Kawamura, Y., Yoshida, A., Nishiyama, M., et al. (2015). Changes in the acetylome and succinylome of Bacillus subtilis in response to carbon source. PLOS ONE 10:e0131169. doi: 10.1371/journal.pone.0131169

Kouzarides, T. (2007). Chromatin modifications and their function. Cell 128, 693-705. doi: 10.1016/j.cell.2007.02.005

Le Roux, C., Huet, G., Jauneau, A., Camborde, L., Tremousaygue, D., Kraut, A., et al. (2015). A receptor pair with an integrated decoy converts pathogen disabling of transcription factors to immunity. Cell 161, 1074-1088. doi: 10.1016/j.cell.2015.04.025

Lee, A. H., Hurley, B., Felsensteiner, C., Yea, C., Ckurshumova, W., Bartetzko, V., et al. (2012). A bacterial acetyltransferase destroys plant microtubule networks and blocks secretion. PLoS Pathog. 8:e1002523. doi: 10.1371/journal.ppat.1002523

Lee, J., Manning, A. J., Wolfgeher, D., Jelenska, J., Cavanaugh, K. A., Xu, H., et al. (2015). Acetylation of an NB-LRR plant immune-effector complex suppresses immunity. Cell Rep. 13, 1670-1682. doi: 10.1016/j.celrep.2015.10.029

Liao, G., Xie, L., Li, X., Cheng, Z., and Xie, J. (2014). Unexpected extensive lysine acetylation in the trump-card antibiotic producer Streptomyces roseosporus revealed by proteome-wide profiling. J. Proteomics 106, 260-269. doi: 10.1016/j.jprot.2014.04.017

Liu, F., Yang, M., Wang, X., Yang, S., Gu, J., Zhou, J., et al. (2014). Acetylome analysis reveals diverse functions of lysine acetylation in Mycobacterium tuberculosis. Mol. Cell. Proteomics 13, 3352-3366. doi: 10.1074/mcp.M114.041962

Liu, X., Liu, S., Bode, L., Liu, C., Zhang, L., Wang, X., et al. (2015). Persistent human Borna disease virus infection modifies the acetylome of human oligodendroglia cells towards higher energy and transporter levels. Virology 485, 58-78. doi: 10.1016/j.virol.2015.06.024
Liu, X., Luo, M., Zhang, W., Zhao, J., Zhang, J., Wu, K., et al. (2012). Histone acetyltransferases in rice (Oryza sativa L.): phylogenetic analysis, subcellular localization and expression. BMC Plant Biol. 12:145. doi: 10.1186/1471-222912-145

Lu, C., and Thompson, C. B. (2012). Metabolic regulation of epigenetics. Cell Metab. 16, 9-17. doi: 10.1016/j.cmet.2012.06.001

Masri, S., Patel, V. R., Eckel-Mahan, K. L., Peleg, S., Forne, I., Ladurner, A. G., et al. (2013). Circadian acetylome reveals regulation of mitochondrial metabolic pathways. Proc. Natl. Acad. Sci. U.S.A. 110, 3339-3344. doi: 10.1073/pnas.1217632110

Melo-Braga, M. N., Verano-Braga, T., Leon, I. R., Antonacci, D., Nogueira, F. C., Thelen, J. J., et al. (2012). Modulation of protein phosphorylation. $\mathrm{N}$-glycosylation and Lys-acetylation in grape (Vitis vinifera) mesocarp and exocarp owing to Lobesia botrana infection. Mol. Cell. Proteomics 11, 945-956.

Mertins, P., Qiao, J. W., Patel, J., Udeshi, N. D., Clauser, K. R., Mani, D. R., et al. (2013). Integrated proteomic analysis of post-translational modifications by serial enrichment. Nat. Methods 10, 634-637. doi: 10.1038/ nmeth. 2518

Mo, R., Yang, M., Chen, Z., Cheng, Z., Yi, X., Li, C., et al. (2015). Acetylome analysis reveals the involvement of lysine acetylation in photosynthesis and carbon metabolism in the model cyanobacterium Synechocystis sp. PCC 6803. J. Proteome Res. 14, 1275-1286. doi: 10.1021/pr501275a

Nagaraj, N., Wisniewski, J. R., Geiger, T., Cox, J., Kircher, M., Kelso, J., et al. (2011). Deep proteome and transcriptome mapping of a human cancer cell line. Mol. Syst. Biol. 7:548. doi: 10.1038/msb.2011.81

Nallamilli, B. R., Edelmann, M. J., Zhong, X., Tan, F., Mujahid, H., Zhang, J., et al. (2014). Global analysis of lysine acetylation suggests the involvement of protein acetylation in diverse biological processes in rice (Oryza sativa). PLoS ONE 9:e89283. doi: 10.1371/journal.pone.0089283

Nie, Z., Zhu, H., Zhou, Y., Wu, C., Liu, Y., Sheng, Q., et al. (2015). Comprehensive profiling of lysine acetylation suggests the widespread function is regulated by protein acetylation in the silkworm. Bombyx mori. Proteomics 15, 3253-3266. doi: 10.1002/pmic.201500001

Okanishi, H., Kim, K., Masui, R., and Kuramitsu, S. (2013). Acetylome with structural mapping reveals the significance of lysine acetylation in Thermus thermophilus. J. Proteome Res. 12, 3952-3968. doi: 10.1021/pr400245k

Pan, J., Ye, Z., Cheng, Z., Peng, X., Wen, L., and Zhao, F. (2014). Systematic analysis of the lysine acetylome in Vibrio parahemolyticus. J. Proteome Res. 13, 3294-3302. doi: 10.1021/pr500133t

Phillips, D. M. (1963). The presence of acetyl groups of histones. Biochem. J. 87, 258-263. doi: 10.1042/bj0870258

Ransom, R. F., and Walton, J. D. (1997). Histone hyperacetylation in maize in response to treatment with $\mathrm{HC}$-Toxin or infection by the filamentous fungus Cochliobolus carbonum. Plant Physiol. 115, 1021-1027.

Sarris, P. F., Duxbury, Z., Huh, S. U., Ma, Y., Segonzac, C., Sklenar, J., et al. (2015). A Plant immune receptor detects pathogen effectors that target WRKY transcription factors. Cell 161, 1089-1100. doi: 10.1016/j.cell.2015. 04.024

Scholz, C., Weinert, B. T., Wagner, S. A., Beli, P., Miyake, Y., Qi, J., et al. (2015). Acetylation site specificities of lysine deacetylase inhibitors in human cells. Nat. Biotechnol. 33, 415-423. doi: 10.1038/nbt.3130

Shen, Y., Wei, W., and Zhou, D. X. (2015). Histone acetylation enzymes coordinate metabolism and gene expression. Trends Plant Sci. 20, 614-621. doi: 10.1016/j.tplants.2015.07.005

Sindhu, A., Chintamanani, S., Brandt, A. S., Zanis, M., Scofield, S. R., and Johal, G. S. (2008). A guardian of grasses: specific origin and conservation of a unique disease-resistance gene in the grass lineage. Proc. Natl. Acad. Sci. U.S.A. 105, 1762-1767. doi: 10.1073/pnas.0711406105

Singh, B. N., Zhang, G., Hwa, Y. L., Li, J., Dowdy, S. C., and Jiang, S. W. (2010). Nonhistone protein acetylation as cancer therapy targets. Expert Rev. Anticancer Ther. 10, 935-954. doi: 10.1586/era.10.62

Smith-Hammond, C. L., Hoyos, E., and Miernyk, J. A. (2014a). The pea seedling mitochondrial Nepsilon-lysine acetylome. Mitochondrion 19(Pt B), 154-165. doi: 10.1016/j.mito.2014.04.012

Smith-Hammond, C. L., Swatek, K. N., Johnston, M. L., Thelen, J. J., and Miernyk, J. A. (2014b). Initial description of the developing soybean seed protein LysN(epsilon)-acetylome. J. Proteomics 96, 56-66. doi: 10.1016/j.jprot.2013.10.038 
Sterner, D. E., and Berger, S. L. (2000). Acetylation of histones and transcription-related factors. Microbiol. Mol. Biol. Rev. 64, 435-459. doi: 10.1128/MMBR.64.2.435-459.2000

Sterner, R., Vidali, G., Heinrikson, R. L., and Allfrey, V. G. (1978). Postsynthetic modification of high mobility group proteins. Evidence that high mobility group proteins are acetylated. J. Biol. Chem. 253, 7601-7604.

Tasset, C., Bernoux, M., Jauneau, A., Pouzet, C., Briere, C., Kieffer-Jacquinod, S., et al. (2010). Autoacetylation of the Ralstonia solanacearum effector PopP2 targets a lysine residue essential for RRS1-R-mediated immunity in Arabidopsis. PLoS Pathog. 6:e1001202. doi: 10.1371/journal.ppat.1001202

Verdin, E., and Ott, M. (2015). 50 years of protein acetylation: from gene regulation to epigenetics, metabolism and beyond. Nat. Rev. Mol. Cell Biol. 16, 258-264. doi: $10.1038 / \mathrm{nrm} 3931$

Walley, J., Xiao, Y., Wang, J. Z., Baidoo, E. E., Keasling, J. D., Shen, Z., et al. (2015). Plastid-produced interorgannellar stress signal MEcPP potentiates induction of the unfolded protein response in endoplasmic reticulum. Proc. Natl. Acad. Sci. U.S.A. 112, 6212-6217. doi: 10.1073/pnas.1504828112

Walley, J. W., Shen, Z., Sartor, R., Wu, K. J., Osborn, J., Smith, L. G., et al. (2013). Reconstruction of protein networks from an atlas of maize seed proteotypes. Proc. Natl. Acad. Sci. U.S.A. 110, E4808-E4817. doi: 10.1073/pnas.1319113110

Wang, C., Ding, Y., Yao, J., Zhang, Y., Sun, Y., Colee, J., et al. (2015). Arabidopsis Elongator subunit 2 positively contributes to resistance to the necrotrophic fungal pathogens Botrytis cinerea and Alternaria brassicicola. Plant J. 83, 10191033. doi: $10.1111 /$ tpj.12946

Wang, Y., An, C., Zhang, X., Yao, J., Zhang, Y., Sun, Y., et al. (2013). The Arabidopsis elongator complex subunit2 epigenetically regulates plant immune responses. Plant Cell 25, 762-776. doi: 10.1105/tpc.113.109116

Weinert, B. T., Wagner, S. A., Horn, H., Henriksen, P., Liu, W. R., Olsen, J. V., et al. (2011). Proteome-wide mapping of the Drosophila acetylome demonstrates a high degree of conservation of lysine acetylation. Sci. Signal. 4:ra48. doi: 10.1126/scisignal.2001902

Wu, Q., Cheng, Z., Zhu, J., Xu, W., Peng, X., Chen, C., et al. (2015). Suberoylanilide hydroxamic acid treatment reveals crosstalks among proteome, ubiquitylome and acetylome in non-small cell lung cancer A549 cell line. Sci. Rep. 5:9520. doi: 10.1038/srep09520

Wu, X., Oh, M. H., Schwarz, E. M., Larue, C. T., Sivaguru, M., Imai, B. S., et al. (2011). Lysine acetylation is a widespread protein modification for diverse proteins in Arabidopsis. Plant Physiol. 155, 1769-1778. doi: 10.1104/pp.110.165852

Wu, X., Vellaichamy, A., Wang, D., Zamdborg, L., Kelleher, N. L., Huber, S. C., et al. (2013). Differential lysine acetylation profiles of Erwinia amylovora strains revealed by proteomics. J. Proteomics 79, 60-71. doi: 10.1016/j.jprot.2012.12.001

Xie, L., Wang, X., Zeng, J., Zhou, M., Duan, X., Li, Q., et al. (2015). Proteomewide lysine acetylation profiling of the human pathogen Mycobacterium tuberculosis. Int. J. Biochem. Cell Biol. 59, 193-202. doi: 10.1016/j.biocel.2014. 11.010

Xu, J., Xu, H., Liu, Y., Wang, X., Xu, Q., and Deng, X. (2015). Genomewide identification of sweet orange (Citrus sinensis) histone modification gene families and their expression analysis during the fruit development and fruit-blue mold infection process. Front. Plant Sci. 6:607. doi: $10.3389 /$ fpls. 2015.00607

Xue, B., Jeffers, V., Sullivan, W. J., and Uversky, V. N. (2013). Protein intrinsic disorder in the acetylome of intracellular and extracellular Toxoplasma gondii. Mol. Biosyst. 9, 645-657. doi: 10.1039/c3mb $25517 \mathrm{~d}$

Yang, L., Vaitheesvaran, B., Hartil, K., Robinson, A. J., Hoopmann, M. R., Eng, J. K., et al. (2011). The fasted/fed mouse metabolic acetylome: N6-acetylation differences suggest acetylation coordinates organspecific fuel switching. J. Proteome Res. 10, 4134-4149. doi: 10.1021/pr2 $00313 \mathrm{x}$

Zhang, K., Zheng, S., Yang, J. S., Chen, Y., and Cheng, Z. (2013). Comprehensive profiling of protein lysine acetylation in Escherichia coli. J. Proteome Res. 12, 844-851. doi: 10.1021/pr300912q

Zhao, S., Xu, W., Jiang, W., Yu, W., Lin, Y., Zhang, T., et al. (2010). Regulation of cellular metabolism by protein lysine acetylation. Science 327, 1000-1004. doi: 10.1126/science.1179689

Zhou, C., Zhang, L., Duan, J., Miki, B., and Wu, K. (2005). HISTONE DEACETYLASE19 is involved in jasmonic acid and ethylene signaling of pathogen response in Arabidopsis. Plant Cell 17, 1196-1204. doi: $10.1105 /$ tpc. 104.028514

Conflict of Interest Statement: The authors declare that the research was conducted in the absence of any commercial or financial relationships that could be construed as a potential conflict of interest.

Copyright (c) 2016 Song and Walley. This is an open-access article distributed under the terms of the Creative Commons Attribution License (CC BY). The use, distribution or reproduction in other forums is permitted, provided the original author(s) or licensor are credited and that the original publication in this journal is cited, in accordance with accepted academic practice. No use, distribution or reproduction is permitted which does not comply with these terms. 